\title{
Effects of pyrite on the spontaneous combustion of coal
}

\author{
Jun Deng ${ }^{1,2} \cdot$ Xiaofeng $\mathrm{Ma}^{1,2} \cdot$ Yutao Zhang ${ }^{1,2} \cdot$ Yaqing $\mathrm{Li}^{1,2} \cdot$ Wenwen $\mathrm{Zhu}^{3}$
}

Received: 3 November 2014/Revised: 27 January 2015/Accepted: 30 March 2015/Published online: 28 September 2015

(C) The Author(s) 2015. This article is published with open access at Springerlink.com

\begin{abstract}
Pyrite has a significant effect on the spontaneous combustion of coal. The presence of pyrite can change the propensity of coal towards spontaneous combustion. The influences of various pyrite contents on the parameters of spontaneous combustion, such as index gases, temperature and released heat etc., were investigated in this study. Coal samples with different pyrite contents $(0 \%, 3 \%, 5 \%, 7 \%$ and $9 \%)$ were made by mixing coal and pyrite. The oxidation experiments under temperature-programmed condition were carried out to test the release rate of gaseous oxidation products at different temperatures. Differential scanning calorimeter (DSC) was employed to measure the intensity of heat release during coal oxidation for various pyrite contents. The results indicate that pyrite can nonlinearly accelerate the process of spontaneous combustion. The coal sample with a pyrite content of $5 \%$ has the largest $\mathrm{CO}$ release rate and oxygen adsorption as well. However, the coal sample with a pyrite content of $7 \%$ has the largest rate of heat flow according to the results from the DSC tests. Pyrite contents of 5\%-7\% in coal has the most significant effects on spontaneous combustion within the range of this study. The conclusions are conducive to the evaluation and control for the spontaneous combustion of coal.
\end{abstract}

Keywords Pyrite $\cdot$ Coal spontaneous combustion $\cdot$ Index gases $\cdot$ Oxidation

\section{Introduction}

The spontaneous combustion of coal is one of the biggest challenges in coal mining. It can cause a series of problems, including significant environmental contamination, temporary or permanent mine closures, environmental problems and even fatalities (Singer et al. 1991; Zhang

Xiaofeng Ma

zytcumt@163.com

1 Xi'an University of Science \& Technology, Xi' an 710054, China

2 Ministry of Education's Key Lab of Mining and Disaster Prevention and Control in Western Mine, Xi' an 710054, China

3 Department of Safety and Quality Management, Inner Mongolia Yitai Coal Co. Ltd., Ordos 017000, Inner Mongolia, China et al. 2011; Bell et al. 2001; Heffern and Coates 2004; Chatterjee 2006; Pone et al. 2007). In China, around $53.1 \%$ of the state-owned coal mines have a propensity towards spontaneous combustion. Also, more than $90 \%$ of coal mine fires resulted from spontaneous combustion of coal (Zhang et al. 2011). Therefore, research on the coal spontaneous combustion mechanism is of importance for fire prevention, detection and extinguishment.

The occurrence and development of coal spontaneous combustion is an extremely complex, dynamic, autoacceleration physical and chemical process. It is affected by a large number of factors such as coal type, moisture content, circumstance temperature, air leakage intensity etc. The effects of sulfur on coal spontaneous combustion have been recognized by most researchers. As the necessity for extending mining depths has grown, the mining of sulfur content coal seams has been significantly increased. Therefore, study of the effects of the sulfur on coal spontaneous combustion has become increasingly vital. 


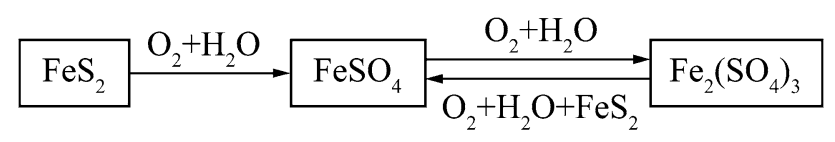

Fig. 1 Reactions of pyrite and oxygen

Three forms of sulfur exist in coal: pyrite, sulfate and organic sulfur (Lu and Liu 1999). Pyrite plays a vital role in coal spontaneous combustion. The specific heat of pyrite is only one-third of that of coal; but with the same heat absorption, the temperature rise of pyrite is three times higher when compared to coal. Reactions of pyrite and oxygen, with the help of moisture, are shown in Fig. 1.

These reactions can occur at low temperatures and additionally, all of the reactions are exothermic reactions. The heat generation from these reactions doubles that of coal with the same oxygen (Garcia 1999; Martínez et al. 2009). Thus, the presence of pyrite is a big promoter for the spontaneous combustion of coal.

Numerous previous studies have been conducted in terms of the characteristics of sulfur in coals. Hakvoort (1995) studied the existing states of sulfur in coal providing fundamentals for the subsequent research. Mondragón et al. (2002) studied the evolution of $\mathrm{H}_{2} \mathrm{~S}$ produced in the reaction of coal and found that the strongest reduction in the amount of $\mathrm{H}_{2} \mathrm{~S}$ evolved was observed in the samples oxidized at $30{ }^{\circ} \mathrm{C}$. The contributive factors for retention effect of sulfur in coal were studied via three bituminous coals by Folgueras et al. (2004). Stanger and Wall (2011) investigated the impacts of sulfur during pulverized coal combustion based on carbon capture. Müller et al. (2013) modeled the evolution of sulfur during coal combustion and divided the whole process into three stages. Chamberlain et al. (2013) experimentally studied the changes of sulfur species $\left(\mathrm{SO}_{2}, \mathrm{H}_{2} \mathrm{~S}, \mathrm{SO}_{3}\right.$ etc.) during the oxidation of coal and quite different concentration distributions were observed at different stages.

As for the impact of sulfur or pyrite on the spontaneous combustion of coal, Shao (1981) pointed that $3 \%$ content of pyrite in coal inhibited positive effects on coal spontaneous combustion in situ where the moisture of coal is proper. Based on the experimental results, Singer et al. (1991) found that the pyrite could non-linearly influence the oxidation process of coal. Guo et al. (2001) investigated the effects of pyrite on the oxidation mechanism of coal. Wen (2011) experimentally studied effects of pyrite on the release rate of $\mathrm{CO}, \mathrm{CO}_{2}, \mathrm{CH}_{4}$. The experimental results indicated that, with the increase of pyrite content, the characteristic parameters of coal spontaneous combustion increases.

In order to fully investigate the influences of sulfur/ pyrite on coal spontaneous combustion, temperature-programmed experiments, oxygen adsorption experiments, and Differential Scanning Calorimeter (DSC) thermal experiments were carried out. The release rate of $\mathrm{CO}$ and $\mathrm{CO}_{2}$, oxygen adsorption amount, and intensity of heat release were employed to evaluate the spontaneous combustion characteristics of coal.

\section{Materials and methods}

\subsection{Sample selection and preparation}

To emphasize the influence of pyrite on the characteristics of coal spontaneous combustion, samples used in the experiments were mixtures of coal and pyrite.

It has been shown that the optimum moisture content for coal oxidation is $14.25 \%$ (Liu 2011). Therefore a lowphosphorus anthracite coal with $10.12 \%$ moisture content was used in the tests.

Coal samples were prepared using two-stage crushing. In the first step, raw coal was crushed to a maximum size of $10 \mathrm{~mm}$ and a $8 \mathrm{~kg}$ sample was collected for mixing with the pyrite for the temperature-programmed experiment. The particle size of the rest of the coal was then reduced to minus $0.2 \mathrm{~mm}$ by secondary crushing. The sulfide used in all the tests was pyrite $\left(\mathrm{FeS}_{2}\right)$ and for the purpose of the experiments, the pyrite ore was also crushed to minus $0.2 \mathrm{~mm}$ in size. The crushed coal and pyrite were then mixed with different ratios. Coal samples with different mass percent of pyrite $(0 \%, 3 \%, 5 \%, 7 \%$ and $9 \%)$ were prepared and kept in dry, sealed glass bottles prior to use in the experiments. Table 1 lists the mass of coal used in each test.

\subsection{Experimental apparatus and methods}

A temperature-programmed system (as shown in Fig. 2) was used to determine the release rate of $\mathrm{CO}$ and $\mathrm{CO}_{2}$. The system contains an oven with programmed temperature control, sample chamber, temperature sensor, and gas chromatograph. A $1200 \mathrm{~g}$ coal sample was used in each test. The temperature of the coal sample was initially $30{ }^{\circ} \mathrm{C}$ and programmed to rise $20{ }^{\circ} \mathrm{C}$ per hour. The air carrier gas was at room temperature with a flow rate of $100 \mathrm{~mL} / \mathrm{min}$.

The oxygen adsorption method is used as a national standard to evaluate the propensity of coal towards spontaneous combustion in China. The oxygen adsorption was analyzed using an Auto GC-4075 coal spontaneous combustion analyzer manufactured by Beijing East-West Instrument Corporation. The size of samples used in this study was minus $0.2 \mathrm{~mm}$, with 6 gram coal samples used in a single test. The flow rate of the carrier gas $\left(\mathrm{N}_{2}\right)$ was $30 \mathrm{~mL} / \mathrm{min}$, and the oxygen inflow was set to $20 \mathrm{~mL} / \mathrm{min}$. Oxygen adsorption at six temperatures $(30,40,50,60,70$, and $80^{\circ} \mathrm{C}$ ) was measured. 
Table 1 Mass of coal in each test at various pyrite contents

\begin{tabular}{lllllll}
\hline Experiments & \multicolumn{2}{l}{ Pyrite content $(\mathrm{g})$} & & \multicolumn{2}{c}{$\begin{array}{c}\text { Coal particle } \\
\text { size }(\mathrm{mm})\end{array}$} \\
\cline { 2 - 5 } & $0 \%$ & $3 \%$ & $5 \%$ & $7 \%$ & $9 \%$ & 1200 \\
\hline Temperature-programmed test & 1200 & 1200 & 1200 & 1200 & $<10$ \\
Oxygen adsorption & 6.0213 & 6.0012 & 6.0143 & 6.0003 & 6.0135 & $<0.2$ \\
DSC & 0.0158 & 0.0146 & 0.0137 & 0.0171 & 0.0143 & $<0.2$ \\
\hline
\end{tabular}

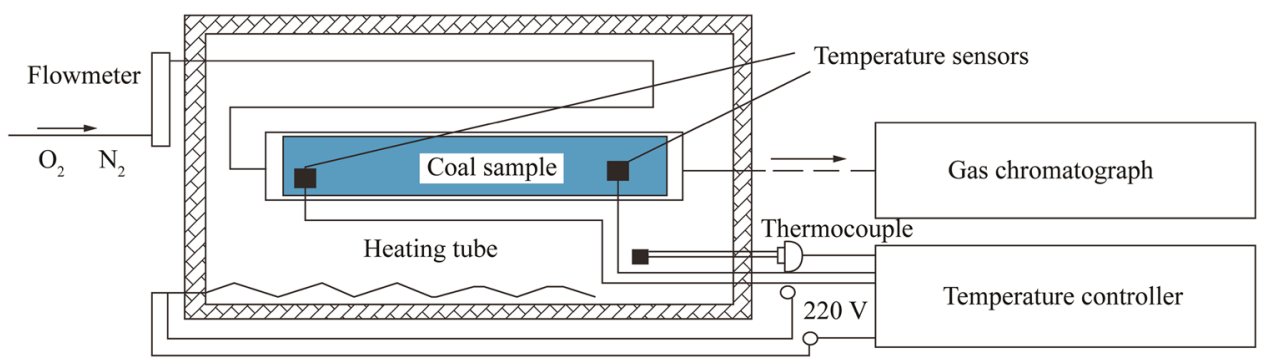

Fig. 2 Temperature-programmed device for the spontaneous combustion of coal

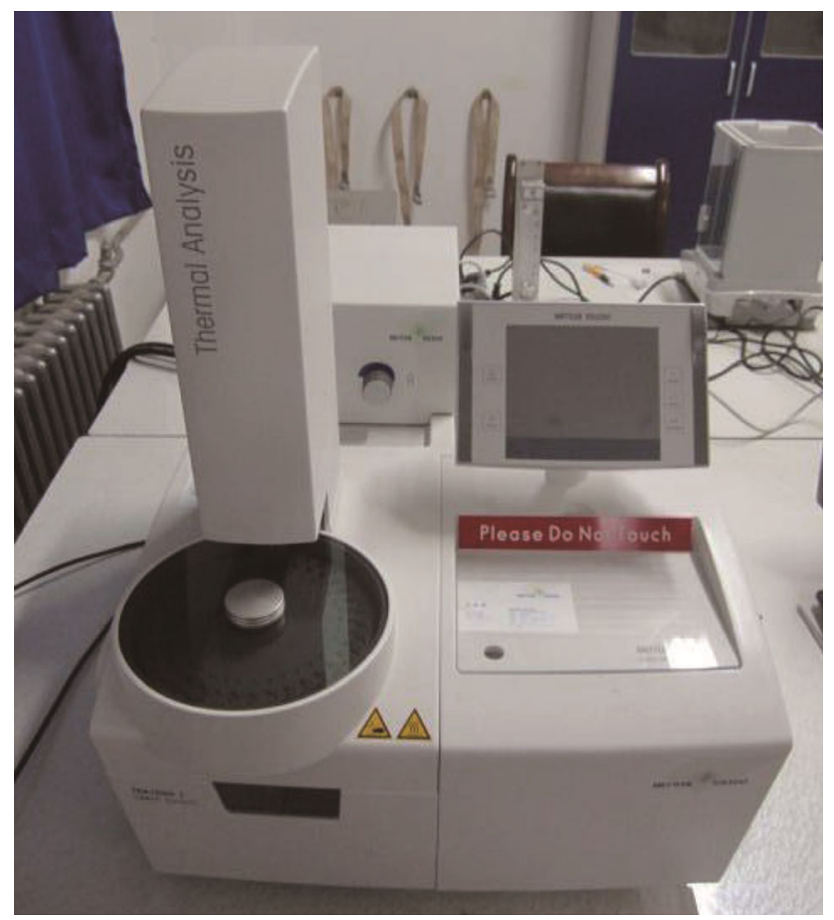

Fig. 3 Thermal analyzer TGA/DSC1 for spontaneous combustion

A thermal analyzer TGA/DSC1, manufactured by Mettler Toledo Corporation, was used in the differential thermal scanning experiments (Fig. 3). In these experiments, a $15 \mathrm{mg}$ coal sample was used and the temperature ranged from $30{ }^{\circ} \mathrm{C}$ to $300{ }^{\circ} \mathrm{C}$. The heating rate was $10{ }^{\circ} \mathrm{C} / \mathrm{min}$ and all the tests were performed in the dynamic air atmosphere with oxygen concentration $21 \%$ and nitrogen $79 \%$. The flow rate of the air was set to be $20 \mathrm{~mL} / \mathrm{min}$.

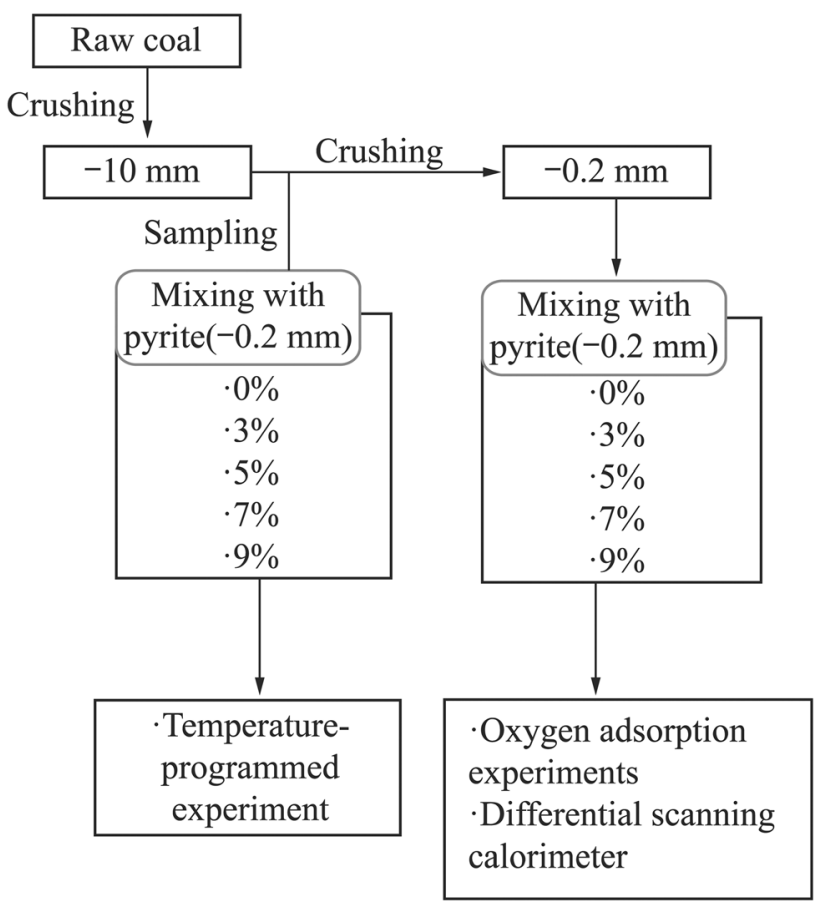

Fig. 4 The flow sheet of the experimental procedure

The basic flow sheet of experiments is given in Fig. 4.

\section{Results and discussions}

\subsection{Temperature-programmed coal oxidation}

The CO profile with different pyrite contents during coal oxidation under the temperature-programmed conditions 
are plotted in Fig. 5. The changes of $\mathrm{CO}$ for various pyrite contents are similar. The $\mathrm{CO}$ concentrations increase gradually at the early stage and sharply after exceeding $100{ }^{\circ} \mathrm{C}$.

Figure 6 illustrates the impact of pyrite content on $\mathrm{CO}$ concentration at different temperatures. Apparently, pyrite has a positive effect on coal oxidation. Nevertheless, the relationship is a little complicated. With the addition of pyrite content in coals, the released $\mathrm{CO}$ during spontaneous combustion increases at the beginning and decreases after exceeding $5 \%$. That is to say, a maximum impact is reached when the pyrite content in coal is $5 \%$. Figure 5 also indicates that the impact of pyrite becomes more significant as the temperature rises due to the heat effect of pyrite.

The release of $\mathrm{CO}_{2}$ during spontaneous combustion is illustrated in Fig. 7. The trends of $\mathrm{CO}$ concentration at different temperatures for various pyrite contents are almost the same. Below $100{ }^{\circ} \mathrm{C}$, the $\mathrm{CO}$ concentration rises gradually as temperature goes up. Between 100 to $120^{\circ} \mathrm{C}$, the release of $\mathrm{CO}$ goes down. After reaching $120^{\circ} \mathrm{C}$, the

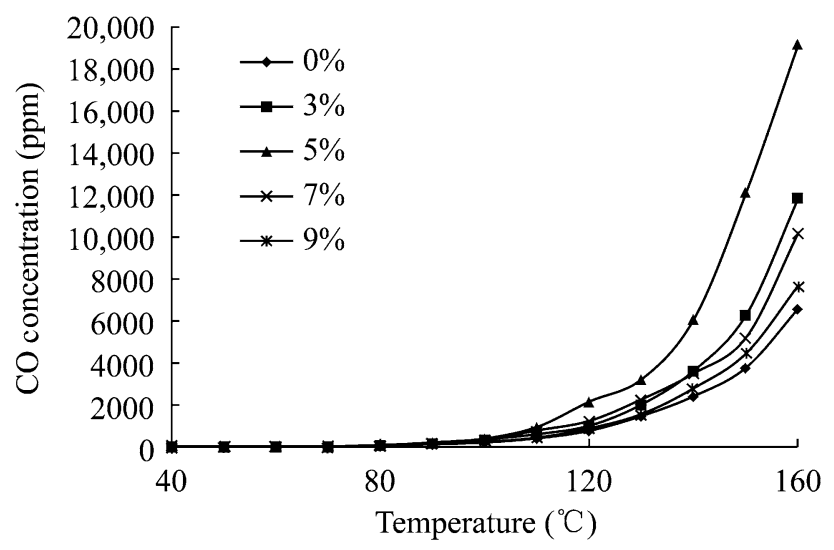

Fig. $5 \mathrm{CO}$ profile during coal oxidation under the temperatureprogrammed conditions

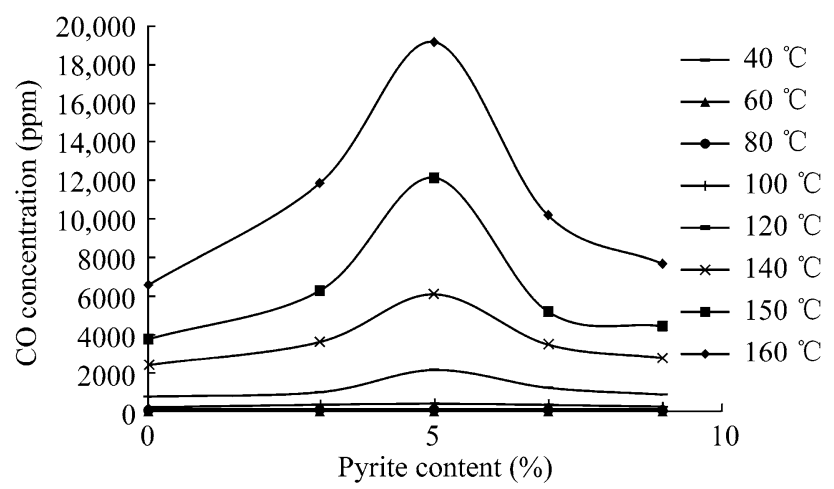

Fig. $6 \mathrm{CO}$ concentration versus pyrite content at different temperatures

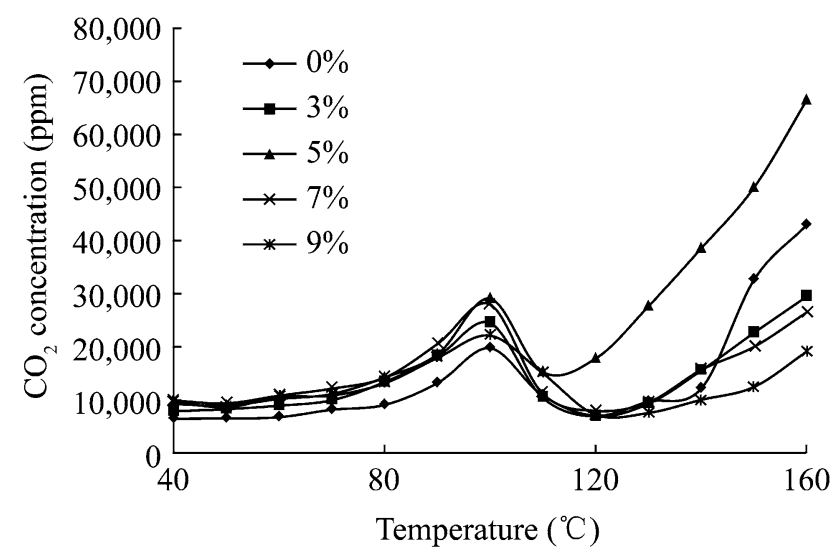

Fig. $7 \mathrm{CO}_{2}$ profile during coal oxidation under the temperatureprogrammed conditions

liberation of $\mathrm{CO}$ increases significantly as temperature rises. The abnormal liberation of $\mathrm{CO}_{2}$ between 100 to $120{ }^{\circ} \mathrm{C}$ might be caused by the evaporation of moisture in the sample. This is indicated by the large amount of water vapor observed at the outlet of the coal oxidation products.

At low temperatures, pyrite does not have a significant effect on spontaneous combustion due to the small amount of released heat. So, the liberations of both $\mathrm{CO}$ and $\mathrm{CO}_{2}$ are small even with varying pyrite contents. As the temperature rises, both Figs. 5 and 7 indicate that $5 \%$ pyrite content in coal has the maximum effect in terms of spontaneous combustion.

\subsection{Oxygen adsorption during spontaneous combustion}

The oxygen adsorption profiles of coal samples at different temperatures for various pyrite contents are presented in Fig. 8.

It is clear from the Fig. 8 that the changes in the oxygen adsorbed by the coal samples show similar trends with temperature rise. The adsorbed oxygen goes down in the early stage and then rises after reaching certain temperatures. That is because physical adsorption, depending on Van der Waals' force, plays a dominant role during the low-temperature oxidation process. With the increase of the temperature, physical adsorption weakens and chemical adsorption becomes gradually stronger. In addition, chemical reaction takes effect after a certain temperature, accelerating the oxygen adsorption.

Figure 8 also shows that the existence of pyrite can promote the oxidation reaction. With the increase of pyrite content, the oxygen adsorption during coal oxidation rises gradually until reaching the maximum at pyrite content of $5 \%$ and decreases afterwards. The pyrite in coals can absorb oxygen and release heat, causing an inflation of coal and therefore accelerating the oxidation process. Besides, 


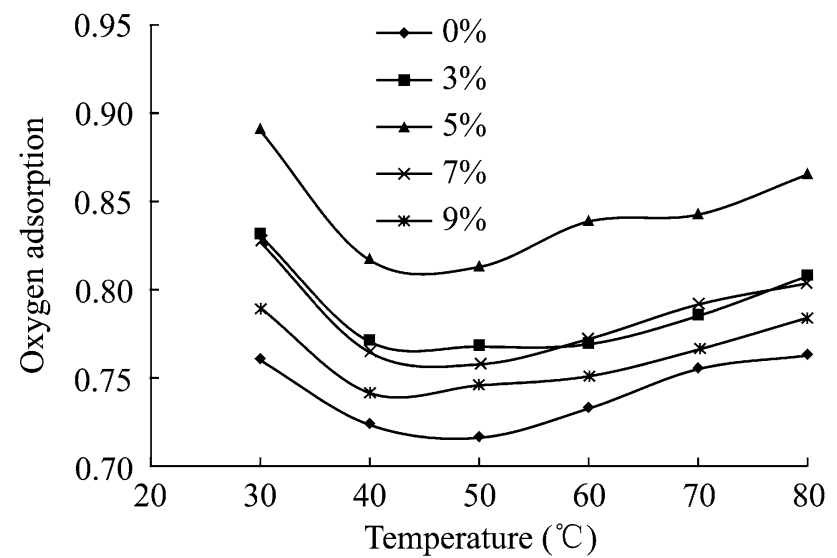

Fig. 8 Oxygen adsorption versus temperature with different pyrite content

sulphuric acid $\left(\mathrm{H}_{2} \mathrm{SO}_{4}\right)$ will be produced during the oxidation of pyrite. The hydrion $\left(\mathrm{H}^{+}\right)$existing in sulphuric acid can absorb a mass of oxygen moleculars, forming a layer of liquid film rich in oxygen ( $\mathrm{Li}$ et al. 2008). So the $\mathrm{H}^{+}$with appropriate concentration can also promote the oxidation reaction. However, oxygen adsorption becomes smaller when the pyrite content is larger than $5 \%$. Two reasons might explain this phenomenon. On the one hand, more pyrite can produce more $\mathrm{H}_{2} \mathrm{SO}_{4}$ as well as more $\mathrm{H}^{+}$. High-concentration $\mathrm{H}^{+}$can hinder the penetration of oxygen molecular through the liquid film; on the other hand, the excessive pyrite is able to transfer to ferric hydroxide $\left(\mathrm{Fe}(\mathrm{OH})_{3}\right)$, a kind of collosol with diameter of 1-100 nm. While the pores among coal moleculars are generally larger than $100 \mathrm{~nm}$, so $\mathrm{Fe}(\mathrm{OH})_{3}$ can enter into the pores and reduce the contact area between coal and oxygen. As a result, the oxidation process was slowed down and the oxygen adsorption was decelerated.

\subsection{Thermal analysis during spontaneous combustion}

DSC technology was utilized to test the impacts of pyrite on the spontaneous combustion of coal. The procedures were described in Sect. 2.2. The profiles of heat flux at different temperatures for various pyrite contents are given in Fig. 9.

Figure 9 indicates that the whole trends of heat flux for all the pyrite contents are similar. At the early stage of the oxidation process, the values of heat flux are negative indicating endothermal reactions, primarily due to the highly humid environments (The moisture content in the coal samples are $10.12 \%$ ). The existence of moisture can absorb the heat and prohibit the chemical reactions as well. Consequently, the oxidation reaction proceeds slowly and so does the endothermal process. As the temperature rises,

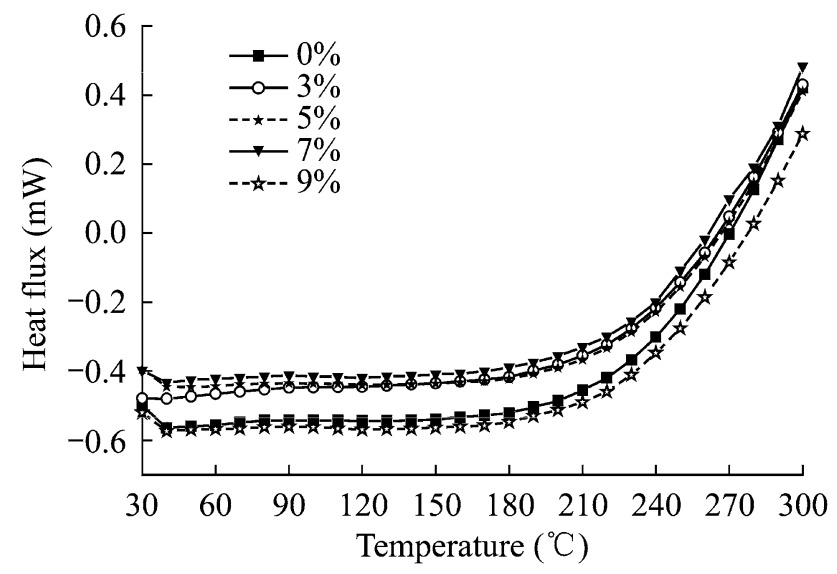

Fig. 9 Changes of heat flux for different pyrite contents

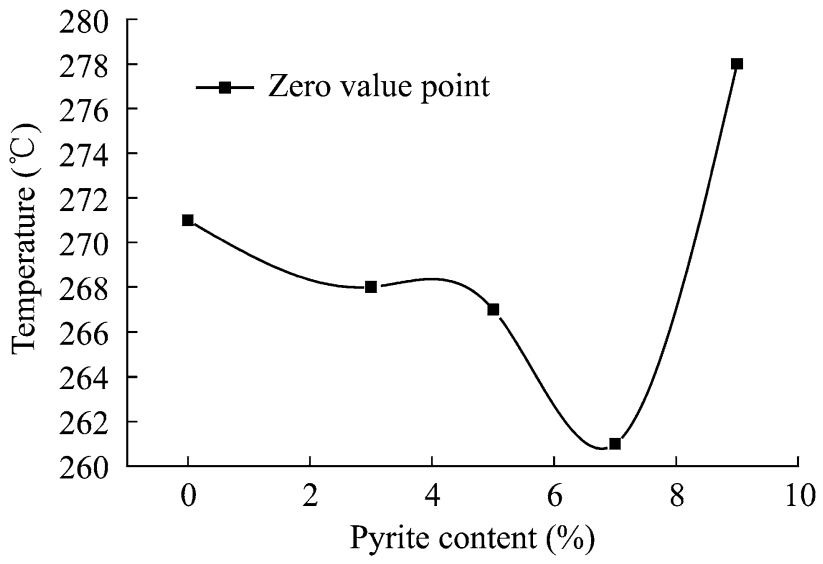

Fig. 10 Zero value points at various pyrite contents

the moisture evaporates and the oxidation reaction speeds up, leading to an increase of heat flux. After the proceeding of the reaction reaches to certain values, the endothermal reaction converts to exothermal reaction.

It can also be seen from Fig. 9 that the heat flux is higher than others all the time when the pyrite content is $7 \%$. When the pyrite content is lower, the heat-absorption effect of pyrite weakens and thus the heat flux reduces. While for a higher pyrite content, the excessive pyrite would produce too much $\mathrm{H}^{+}$covering the coal surface and a lot of $\mathrm{Fe}(\mathrm{OH})_{3}$ penetrating into the coal pores so as to prohibit the oxidation process and therefore reduce the heat flux.

The zero value point on the DSC curve is defined as the conversion point from endothermal reaction to exothermal reaction. A lower zero value point represents a stronger exothermal capacity. The zero value points at various pyrite contents were plotted in Fig. 10.

Figure 10 indicates that with the increase of the pyrite contents, the zero value points decrease at the beginning and increase after reaching a certain point $(7 \%$ in this experiment). A lower zero value point means the self- 
sustaining reaction will be realized more quickly. Thus, the lower zero value point, to some extent, can be used to evaluate the propensity of coal towards spontaneous combustion. So, the coal sample with a pyrite content of $7 \%$ in this experiment is the easiest to spontaneously combust.

\section{Conclusions}

Spontaneous combustion is always a big challenge in underground coal mining, storage and transportation. Of the factors impacting spontaneous combustion, pyrite content plays an important role. The influence of pyrite with different contents on spontaneous combustion was investigated. This study shows that pyrite can tremendously promote the spontaneous combustion of coal.

Through coal oxidation under temperature-programmed condition, the release rates of $\mathrm{CO}$ and $\mathrm{CO}_{2}$ at different pyrite contents were obtained. The released $\mathrm{CO}$ during spontaneous combustion increases slowly at the early stage and sharply as the temperature rises. The experimental results indicated that the coal sample with a pyrite content of $5 \%$ had the maximum promotion in terms of spontaneous combustion. The oxygen adsorption experiments further confirmed this conclusion. However, the coal sample with a pyrite content of $7 \%$ had the largest heat flux according to the results from the DSC tests. The proposed zero value point can be used to evaluate the propensity of coal towards spontaneous combustion. The conclusions are helpful when dealing with the spontaneous combustion issues in the field.

Acknowledgments The financial supports for this research, provided by the National Natural Science Foundation of China (51404192), fund for the China Postdoctoral Science Foundation (2014M552555XB, 2015T81043), Natural Science Foundation of Shaanxi Province (2015JQ5174) and Scientific Research Program Funded by Shaanxi Provincial Education Department (14JK1476) are greatly acknowledged.

Open Access This article is distributed under the terms of the Creative Commons Attribution 4.0 International License (http://crea tivecommons.org/licenses/by/4.0/), which permits unrestricted use, distribution, and reproduction in any medium, provided you give appropriate credit to the original author(s) and the source, provide a link to the Creative Commons license, and indicate if changes were made.

\section{References}

Bell FG, Bullock SET, Halbich TFJ, Lindsayd P (2001) Environmental impacts associated with an abandoned mine in the
Witbank Coalfied, South Africa. Int J Coal Geol 45(2-3): 195-216

Chamberlain S, Reeder T, Stimpson CK, Tree DR (2013) A comparison of sulfur and chlorine gas species in pulverizedcoal, air- and oxy-combustion. Combust Flame 160(11):2529 2539

Chatterjee RS (2006) Coal fire mapping from satellite thermal IR data: a case example in Jharia Coalfield, Jharkhand, India. ISPRS J Photogramm Remote Sens 60(2):113-128

Folgueras MB, Díaz RM, Xiberta J (2004) Sulphur retention during co-combustion of coal and sewage sludge. Fuel 83(10): $1315-1322$

Garcia P (1999) The use of differential scanning calorimetry to identify coal ssusceptible to spontaneous combustion. Thermochim Acta 336(1):41-46

Guo X, Xu J, Hui S (2001) Investigation on air leakage law of gate coal seam. J Xi' an Jiaotong Univ 25(3):239-243

Hakvoort G (1995) Regenerable sulfur sorbents in coal combustion. Thermodynamics and testing by TG. Recent Adv Thermal Anal Calorim 269:697-704

Heffern EL, Coates DA (2004) Geologic history of natural coal-bed fires, Powder River Basin, USA. Int J Coal Geol 59(1):25-47

Li S, Xiao J, Peng Q (2008) The effects of sulfur in coals. Land Resour Herald Technol 5(3):35-37

Liu W (2011) Effects of high moisture atmosphere on the characteristics of coal spontaneous combustion. Master's Thesis's. Xi' an University of Science and Technology

Lu M, Liu W (1999) Sulfur distribution of high sulfur coal and feasibility study of coal desulfurization before combustion. Coal Sci Technol 27(2):42-46

Martínez M, Márquezb G, Alejandrec FJ, Del Ríoc JJ, Hurtado A (2009) Geochemical study of products associated with spontaneous oxidation of coal in the Cerro Pelado Formation, Venezuela. J S Am Earth Sci 27(2):211-218

Mondragón F, Ruíz W, Santamaŕia A (2002) Effect of early stages of coal oxidation on its reaction with elemental sulphur. Fuel 81(3):381-388

Müller M, Schnell U, Scheffknecht G (2013) Modelling the fate of sulphur during pulverized coal combustion under conventional and oxy-fuel conditions. Energy Procedia 37:1377-1388

Pone J, Denis N, Hein Kim AA, Glenn SB (2007) The spontaneous combustion of coal and its by-products in the Witbank and Sasolburg Coalfields of South Africa. Int J Coal Geol 72(2):124-140

Shao QY (1981) Effects of sulfur on coal spontaneous combustion. Min Saf Environ Prot 1:1-8

Singer RN, Demille S, Yu MG (1991) Effects of sulfide and ferrum on coal spontaneous combustion. Min Saf Environ Prot 2:57-62

Stanger R, Wall T (2011) Sulphur impacts during pulverised coal combustion in oxy-fuel technology for carbon capture and storage. Prog Energy Combust Sci 37(1):69-88

Wen H (2011) Experiment research on effect of sulfur on characteristic parameters of coal spontaneous combustion. Saf Coal Mines 42(10):5-7

Zhang Y, Lai Y, Huang Z, Gao Y (2011) Study on small simulation device of coal spontaneous combustion process. Procedia Eng 26:922-927 